\title{
Selective Flotation-Spectrophotometric Procedure for the Trace Analysis of Palladium(II) in Different Matrices
}

\author{
Mohamed A. KABIL ${ }^{\dagger}$, Magda A. AKL and Magdy E. KHALIFA \\ Chemistry Department, Faculty of Science, Mansoura University, P. O. Box 15, Egypt
}

\begin{abstract}
2-Hydroxyimino-3-(2-hydrazonopyridyl)-butane (HHB) was investigated as a new reagent for the flotation of palladium(II). The metal ion forms a 1:1 pale-violet complex with HHB in aqueous solution. An intense clear violet layer was formed, after flotation, by adding an oleic acid (HOL) surfactant. The composition of the float is 1:1 (Pd:HHB). A highly selective and sensitive spectrophotometric procedure was proposed for the determination of microamounts of $\mathrm{Pd}(\mathrm{II})$ as its floated complex. The flotation-determination method was achieved in the $\mathrm{pH}$ range $2.5-$ 7.0. Beer's law was obeyed up to $6 \times 10^{-5} \mathrm{~mol}^{-1}(6.3 \mathrm{ppm})$. Interference from various foreign ions was avoided by adding excess HHB. The molar absorptivities of Pd-HHB and Pd-HHB-HOL systems are $2.5 \times 10^{3}$ and $2.1 \times 10^{4} 1 \mathrm{~mol}^{-1}$ $\mathrm{cm}^{-1}$ at $555 \mathrm{~nm}$, each. The formation constants of the species formed in the presence and absence of HOL are $9 \times 10^{5}$ and $4.6 \times 10^{7} 1 \mathrm{~mol}^{-1}$, respectively. The method was successfully applied to the analysis of $\mathrm{Pd}(\mathrm{II})$ in simulated ores, complexes, and water samples. The separation mechanism is discussed.
\end{abstract}

Keywords Palladium, 2-hydroxyimino-3-(2-hydrazonopyridyl)-butane, flotation, spectrophotometry

The determination of palladium under microgram concentration levels is generally hampered by insufficient sensitivity of the techniques used and or by a matrix effect. With the introduction of techniques, sensitivity problems have been drastically reduced.

There are chemical and physical methods to increase the sensitivity and decreasing matrix effects, such as extraction ${ }^{1,2}$ or preconcentration by solvent evaporation; however, in the presence of complex matrices with very low concentration of the analyte, these methods are seldom effective and are considered to be unsatisfactory. However, the development of a sensitive, accurate, precise and fast procedure using less sophisticated instruments is a vital process.

The formation of extractable chelates of Pd(II) with dithizone $^{3}$ and dithiocarbamate ${ }^{4}$ has been applied to the separation of $\mathrm{Pd}(\mathrm{II})$ from other platinum metal ions. Also, the extraction of Pd(II) halide complexes affords convenient separation. ${ }^{5}$ Oxime derivatives have also been used for extraction and the spectrophotometric determination of $\mathrm{Pd}(\mathrm{II})$.

Flotation techniques are recommended as good separation and preconcentration ${ }^{6-8}$ tools with most of the advancing factors previously mentioned. Recently, the flotation-separation step can be analytically completed spectrophotometrically ${ }^{9}$ or by a suitable technique, such as atomic absorption spectrometry. ${ }^{10}$ Such techniques acquire analytical importance as the flotation-separation step is selectively completed.

Although many spectrophotometric methods have been reported for the determination of $\mathrm{Pd}(\mathrm{II})^{6-8}$, a sim-

$\doteqdot$ To whom correspondence should be addressed. ple, rapid and economical flotation-spectrophotometric method has been developed for the concentration and determination of trace $\mathrm{Pd}(\mathrm{II})$ in different matrices using HOL as a surfactant and HHB as a chelating reagent. This reagent is more sensitive and specific than many of the reagents reported for $\mathrm{Pd}(\mathrm{II}){ }^{3,4}$ Moreover, this method involves the determination of trace $\mathrm{Pd}(\mathrm{II})$ after selective separation by floatation, those eliminating the effect of foreign ions and increasing the sensitivity. Also, the direct determination of $\mathrm{Pd}(\mathrm{II})$ in the surfactant phase decreases its determination time and loss during the determination. Another advantage of the present investigation is that the data obtained spectrophotometrically were attained by the simplest colorimetric analysis method.

A literature survey showed that ion-flotation followed by a spectrophotometric determination of $\mathrm{Pd}(\mathrm{II})$ is rarely reported. ${ }^{11,12}$ Also, no attempt has been found for using HHB in this concern. Fortunately, in this investigation, HHB finds its role for a direct spectrophotometric determination of $\mathrm{Pd}(\mathrm{II})$, and also gives high performance in the preconcentration of Pd(II) via its flotation as HHB-Pd colligend.

\section{Experimental}

\section{Reagents}

Palladium stock solutions were prepared by dissolving $1 \mathrm{~g} \mathrm{PdCl}_{2}$ (Merck) in $3 \mathrm{ml} \mathrm{HCl}$ followed by dilution to $250 \mathrm{ml}$ using doubly distilled water or ethanol. For the analysis of simulated ores, a Pd stock solution was prepared by dissolving $1 \mathrm{~g}$ of $\mathrm{Pd}$ wire in few $\mathrm{ml}$ of 
$\mathrm{HNO}_{3}$, followed by dilution with doubly distilled water to $250 \mathrm{ml}$. The final concentration of Pd(II) was standardized using an atomic-absorption spectrometer.

The reagent HHB was prepared as previously reported. ${ }^{12}$ The purity of HHB has been confirmed by TLC and HPLC analyses. A $1 \times 10^{-3} \mathrm{~mol} \mathrm{l}^{-1}$ stock HHB solution was prepared by dissolving the requisite amount in an aqueous ethanolic solution.

An oleic acid stock solution $\left(6.36 \times 10^{-2} \mathrm{~mol} \mathrm{l}^{-1}\right.$ was prepared by dispersing $20 \mathrm{ml}$ of HOL (food grade) sp.gr. 0.895 , provided by J. T. Baker Chemical Co.) in one liter of kerosene.

All other reagents were of analytical-reagent grade.

\section{Apparatus}

The flotation cell used was a cylindrical graduated glass tube of $16 \mathrm{~mm}$ inner diameter and $290 \mathrm{~mm}$ length with a stopper at the top and a stopcock at the bottom. The spectral data were recorded on Unicam UV 2100 UV/Vis and MATTSON 5000 FTIR spectrometers.

The $\mathrm{pH}$ values of all solutions were measured using a Hanna Instruments 8519 digital $\mathrm{pH}$ meter.

The atomic absorption measurements were recorded using a Perkin-Elmer 2380 atomic-absorption spectrophotometer with an air-acetylene flame. The optimum parameters for Pd measurements are: wavelength, $244.8 \mathrm{~nm}$; lamp current, $15 \mathrm{~mA}$; burner height, $0.9 \mathrm{~cm}$; slit width, $0.7 \mathrm{~mm}$; fuel flow rate, $31 \mathrm{~min}^{-1}$; and air flow rate, $21 \mathrm{~min}^{-1}$.

\section{Spearation and determination procedure of $P d(I I)$}

After suitable concentrations of $\mathrm{Pd}(\mathrm{II})$ and HHB were mixed, $3 \mathrm{ml}$ of doubly distilled water was added. The $\mathrm{pH}$ was adjusted to the optimum value (3.5). The solution was then transferred quantitatively to a flotation cell and completed to $10 \mathrm{ml}$ with doubly distilled water. The cell was shaken well for few seconds to ensure complete complexation. To this solution, $3 \mathrm{ml}$ of HOL $\left(10^{-4} \mathrm{~mol} \mathrm{l}^{-1}\right)$ was added. The flotation cell was then inverted upsidedown twenty times by hand. After complete flotation $(10 \mathrm{~min})$ the scum layer was separated and taken for the determination of $\mathrm{Pd}(\mathrm{II})$ by atomic absorption spectrometry (AAS) after eluting the analyte with a few drops of $\mathrm{HNO}_{3}$ or $\mathrm{HCl}$. Also, $\mathrm{Pd}(\mathrm{II})$ was determined directly by AAS in the mother liquor. The separation efficiency (S\%) of the analyte was calculated from its concentration in the mother liquor according to the relation

$$
S=\left[\left(c_{\mathrm{i}}-c_{\mathrm{f}}\right) / c_{\mathrm{i}}\right] \times 100 \%,
$$

where $c_{\mathrm{i}}$ and $c_{\mathrm{f}}$ denote the initial and final concentrations of the analyte, respectively.

Alternatively, the analyte concentration was directly measured spectrophotometrically at $555 \mathrm{~nm}$. The separation efficiency was calculated from the relation

$$
F=\left(c_{\mathrm{s}} / c_{\mathrm{i}}\right) \times 100 \%,
$$

where $c_{\mathrm{i}}$ and $c_{\mathrm{s}}$ are the initial and scum concentrations of the analyte, respectively.

\section{Results and Discussion}

\section{Separation and microdetermination of $P d(I I)$}

Separation-flotation. In the solvent sublation technique oleic acid imposed itself as an excellent surfactant for the selective separation of some metal ions as soluble intense colored compounds in the scum layer. ${ }^{13}$ Consequently, such processing enables and facilitates the spectrophotometric determination of the analyte.

A conductive series of experiments was carried out to float $\mathrm{Pd}(\mathrm{II})$ using $\mathrm{HOL}$ alone. A suitable concentration of the analyte $\left(2 \times 10^{-5} \mathrm{~mol} \mathrm{l}^{-1}\right)$ was taken in the flotation cell and a sufficient quantity of HOL surfactant $\left(2 \times 10^{-4}\right.$ mol $1^{-1}$ ), which is still less than the critical micelle concentration (CMC) was added to float Pd(II) at different $\mathrm{pH}$ values. The data in Fig. 1 (curve a) prove that not more than $80 \%$ of the analyte was separated at any $\mathrm{pH}$. Such a separation percent is not analytically satisfactory in which $\mathrm{Pd}(\mathrm{II})$ floats as Pd-oleate. ${ }^{14}$ Accordingly, many trials were carried out to separate $\mathrm{Pd}(\mathrm{II})$ quantitatively and selectively using different organic collectors. Of these, HHB imposed itself as an excellent collector. The data in Fig. 1 (curve b) show that complete separation $(\approx 100 \%)$ of $\mathrm{Pd}(\mathrm{II})$ was obtained in the $2.5-7.0 \mathrm{pH}$ range in the presence of $2 \times 10^{-4} \mathrm{~mol} \mathrm{l}^{-1}$ of HHB. In such a case, Pd(II) floats in the form of the Pd-HHB complex as an intense violet color.

The data in Fig. 1 show that complete separation of the analyte is achieved over a wide range of $\mathrm{pH}$. The direct addition of the reactants acquires the solution $\mathrm{pH}=3.5$. Accordingly, $\mathrm{pH} 3.5$ is selected as a suitable value for complete separation to facilitate the proposed afford due to the progress in this experimental investigation. At such $\mathrm{pH}$, a conductive series of experiments was carried

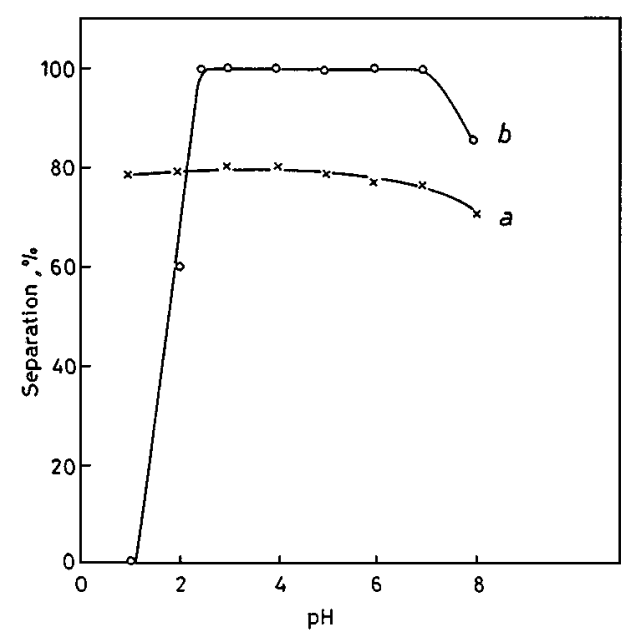

Fig. 1 Effect of the $\mathrm{pH}$ on the separation efficiency of $2 \times 10^{-5}$ mol $1^{-1} \mathrm{Pd}(\mathrm{II})$ : a) in the absence of $\left.\mathrm{HHB}, \mathrm{b}\right)$ in the presence of $2 \times 10^{-4} \mathrm{~mol} \mathrm{l}^{-1} \mathrm{HHB}$, using $2 \times 10^{-4} \mathrm{~mol} \mathrm{l}^{-1} \mathrm{HOL}$. 


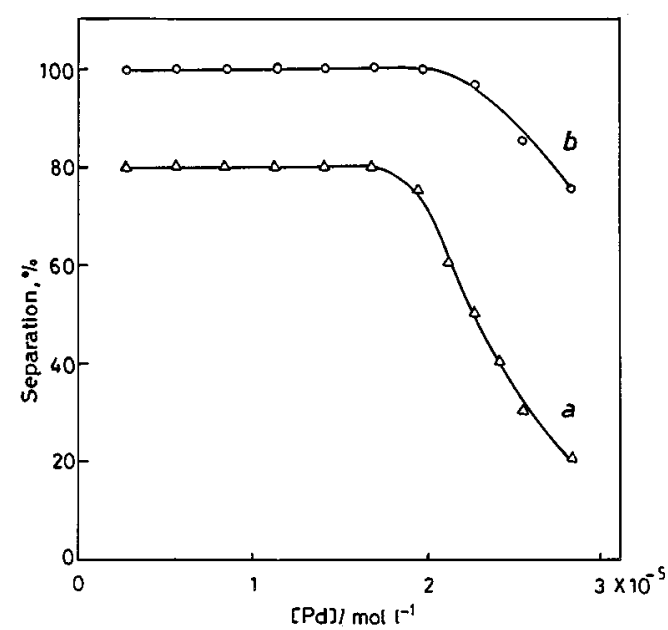

Fig. 2 Floatability of different concentrations of $\mathrm{Pd}(\mathrm{II})$ at $\mathrm{pH}$ 3.5: a) in the absence of HHB, b) in the presence of $2 \times 10^{-5}$ mol 1-1 $\mathrm{HHB}$ using $2 \times 10^{-4} \mathrm{~mol} \mathrm{l}^{-1} \mathrm{HOL}$.

out to investigate the type of interaction between $\mathrm{Pd}(\mathrm{II})$ and HHB in solution. It was found that $\mathrm{Pd}(\mathrm{II})$ forms a 1:1 complex with HHB, and complete flotation-separation was achieved whatever amount of HHB was added. This simplifies the procedure for the analytical separation and determination of $\mathrm{Pd}(\mathrm{II})$, especially in samples containing unknown amounts of the analyte.

To confirm the previous data, another series of experimental work was carried out by changing the metal concentration. The data (Fig. 2) showed that complete separation occurred up to the previous ratio of $1: 1$. Above such a ratio of increasing Pd(II), curve (b) in Fig. 2 attains a small degradation to a lower separation percentage. This reflects that insufficient ligand is present for complete complexation and indirect separation.

The floatability of $\mathrm{Pd}(\mathrm{II})$ at different concentrations of HOL in the absence (Fig. 3, curve a) and presence (curve b) of HHB has been investigated. Curve (a) shows that the floatability of $\mathrm{Pd}(\mathrm{II})$ slightly increases and reaches $80 \%$ over a wide concentration range of HOL, and then again slightly decreases. Curve (b) shows a similar trend, but with a maximum floatability (100\%). Again, the effect of HHB is evident from a comparison of curves (a) and (b). Thus, $2 \times 10^{-4} \mathrm{~mol}^{-1}$ HOL was used throughout this work.

Spectrophotometric determination. First of all, it should be noted that the maximum absorbance of the complex Pd-HHB corresponds to its maximum flotation efficiency. Accordingly, the maximum absorbance can be expressed by the maximum separation; also, the reverse is true.

A series of experiments provided valuable data for complete elution of the total content of palladium by acidifying the scum layer with $\mathrm{HCl}$ or $\mathrm{HNO}_{3}$. The palladium content in the eluted solution was determined by AAS, after adding a suitable leveling-off agent, as previously mentioned in the literature ${ }^{15}$, as a confirmatory tool for supporting the proposed spectrophotometric

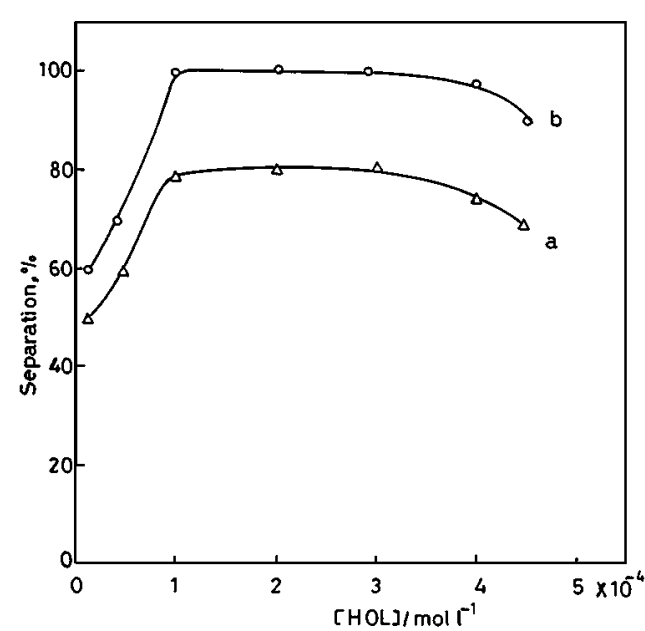

Fig. 3 Floatability of $\mathrm{Pd}(\mathrm{II}), 2 \times 10^{-5} \mathrm{~mol}^{-1} v s$. HOL concentration: a) in the absence of $\mathrm{HHB}$ and $b$ ) in the presence of $2 \times 10^{-4} \mathrm{~mol} \mathrm{l}^{-1} \mathrm{HHB}$ at $\mathrm{pH} 3.5$.

procedure in this study. Such a procedure is based on the formation of a violet-colored complex between palladium and HHB. This color becomes deep in the scum layer, even at trace amounts of the original palladium.

The absorption spectra of the Pd-HHB system in the aqueous solution and in the scum are completely different from that of palladium and HHB. It is observed that: 1) the $\lambda_{\max }$ of Pd-HHB exhibits a red shift (345 $\mathrm{nm}$ ) from that of HHB and 2) the absorbance of PdHHB-HOL system exhibits nearly 8-fold that of PdHHB. This proves that the species are highly concentrated in the presence of HOL. The complex formed in the scum layer exhibits two maxima at 555 and $590 \mathrm{~nm}$ (Fig. 4). The measurements at $590 \mathrm{~nm}$ are not satisfactory from an analytical point of view in which Beer's law is not obeyed. Consequently, all of the following spectrophotometric measurements were recorded at 555 $\mathrm{nm}$. The stoichiometry of the complexes formed in solution and scum was ascertained by applying the continuous variation method. ${ }^{16}$ However, in all measurements, the same concentration of HHB as in the test solution was used as a blank.

The results (Fig. 5) reveal the possible formation of the 1:1 (Pd-HHB) species in the two systems. The apparent formation constant $\left(K_{\mathrm{f}}\right)$ of the complexes formed in the absence and presence of HOL are $9 \times 10^{5}$ and $4.6 \times 10^{7} 1 \mathrm{~mol}^{-1}$, respectively. Thus, the stability of the species formed in the presence of HOL is higher than that obtained in its absence. Therefore, HOL stabilizes the complex formed more than does water. It has been found that Beer's law is obeyed up to $6 \times 10^{-5}$ mol $1^{-1}(6.3 \mathrm{ppm})$ and the molar absorptivities are $2.5 \times 10^{3}$ and $2.1 \times 10^{4} 1 \mathrm{~mol}^{-1} \mathrm{~cm}^{-1}$ for species in the aqueous and scum, respectively. The regular enhancement in the absorbances and the higher molar absorptivity value in the presence of HOL could be attributed to the selective separation of Pd-HHB using the HOL surfactant. 


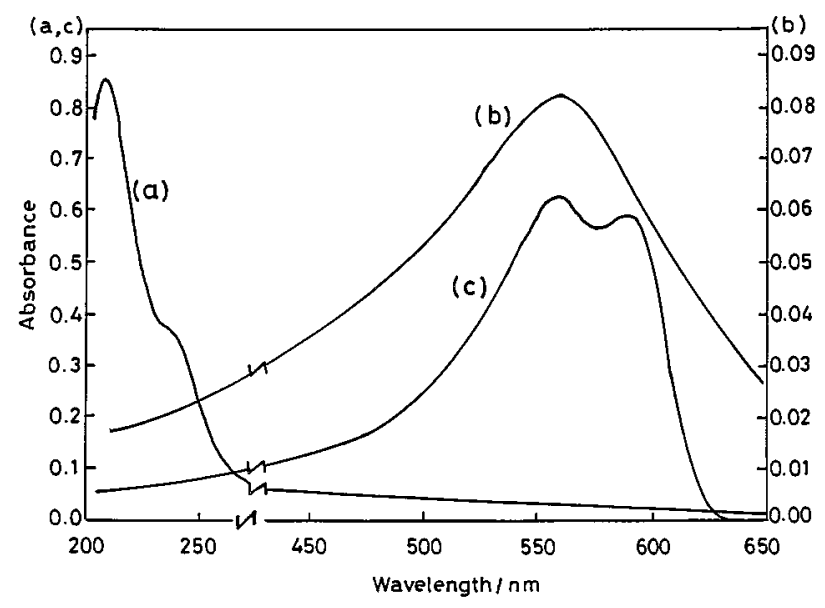

Fig. 4 Absorption spectra of: a) the reagent HHB, b) Pd-HHB system and c) Pd-HHB-HOL system.

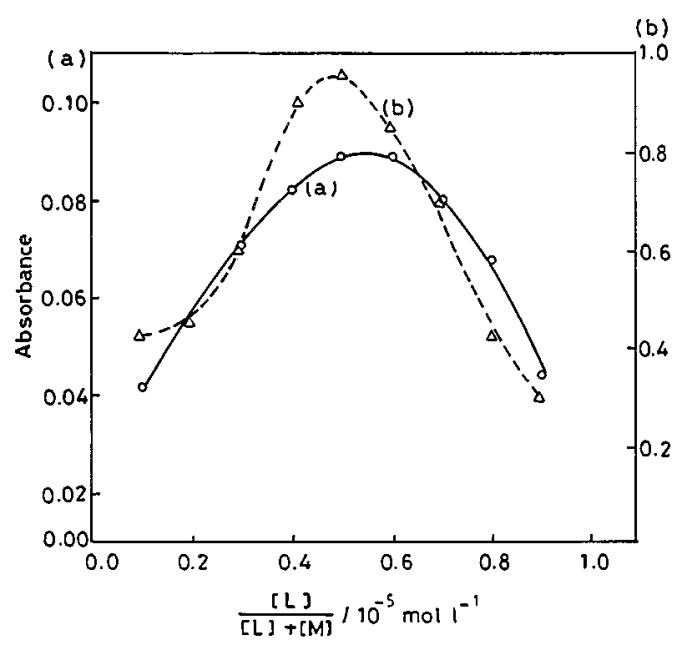

Fig. 5 Continuous variation method for a) Pd-HHB system at $555 \mathrm{~nm}$ and b) Pd-HHB-HOL system at $555 \mathrm{~nm}$.

On the other hand, although the complex is formed in the aqueous solution and obeys Beer's law, its absorbance and $\varepsilon$ values are very low. Also, Beer's law is obeyed in a very narrow concentration range. These defects may favor the determination of palladium after preconcentration. The limit of detection, which was calculated as the concentration that gives a reading equal to twice the standard deviation of a series of ten determinations taken with solutions of concentrations, which are close to the level of the blank, was found to be $2.4 \times 10^{-7} \mathrm{~mol} \mathrm{l}^{-1}$. Also, in this concern a fixed quantity of $\mathrm{Pd}(\mathrm{II})$ was taken and added to different aqueous volumes. It was found that $7.5 \times 10^{-7} \mathrm{~mol} \mathrm{l}^{-1}$ of $\mathrm{Pd}(\mathrm{II})$ was quantitatively separated and determined from different volumes up to $1 \mathrm{l}$. This means that $79.8 \mathrm{ppb}$ of $\operatorname{Pd}(\mathrm{II})$ can be safely separated and spectrophotometrically determined by such a procedure from a one-liter solution into $20 \mathrm{ml}$ of $\mathrm{HOL}\left(2 \times 10^{-4} \mathrm{~mol} \mathrm{l}^{-1}\right)$.

The effect of foreign metal ions on the floatability of Pd(II) with HHB has been studied in detail. The

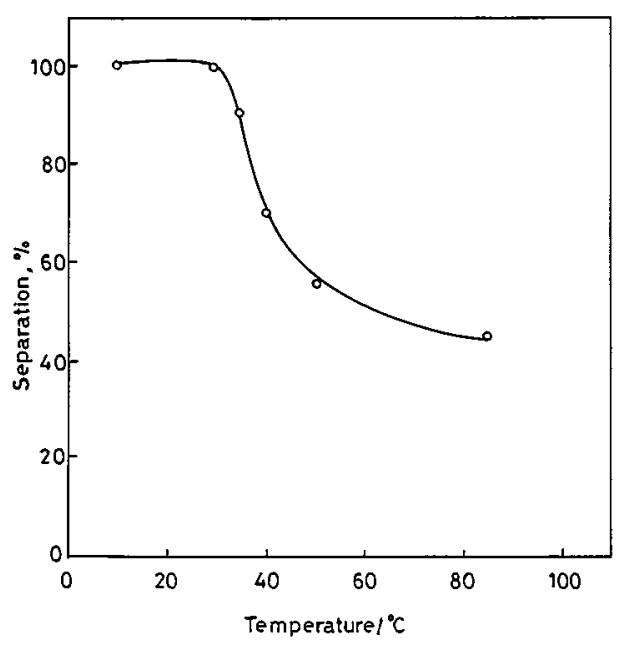

Fig. 6 Effect of temperature on the separation efficiency of $2 \times 10^{-5} \mathrm{~mol} \mathrm{l}^{-1} \mathrm{Pd}(\mathrm{II})$ at $\mathrm{pH} 3.5$ in the presence of $4 \times 10^{-4} \mathrm{~mol}$ $\mathrm{l}^{-1} \mathrm{HHB}$ using $2 \times 10^{-4} \mathrm{~mol}^{-1} \mathrm{HOL}$.

obtained results reveal that in spite of the high tendency of HHB to form complexes with different transition metal ions, fortunately, most of these complexes are not floated with the $\mathrm{Pd}(\mathrm{II})$ complex at $\mathrm{pH} 2.5-3.5$. The experimental data showed that $\mathrm{Na}(\mathrm{I}), \mathrm{K}(\mathrm{I}), \mathrm{Ag}(\mathrm{I})$, $\mathrm{Ca}(\mathrm{II}), \mathrm{Mg}(\mathrm{II}), \mathrm{Sr}(\mathrm{II}), \mathrm{Pb}(\mathrm{II}), \mathrm{Cd}(\mathrm{II})$ and $\mathrm{Ni}(\mathrm{II})$ as chlorides, sulfates or nitrates have no effect, whereas $\mathrm{Cu}(\mathrm{II}), \mathrm{Al}(\mathrm{III}), \mathrm{Hg}$ (II), $\mathrm{Fe}$ (III), U(IV), V(V) and Os(V) have little interfering effects $(\sim 1 \%)$. All of these interferences were completely controlled by adding excess HHB $\left(2 \times 10^{-4} \mathrm{~mol} \mathrm{l}^{-1}\right)$. Hence, one can predict that the interfering effects may be due to complex formation which is accompanied by a decrease in the ligand concentration. Consequently, masking of the interfering effects by adding excess HHB offers a highly selective procedure for the separation and determination of microamounts of $\mathrm{Pd}(\mathrm{II})$ in various complex materials, like environmental and biological samples.

\section{Flotation mechanism}

In studies concerning separation via flotation, the role of surfactant is very important. The nature of the interaction between oleic acid surfactant and the complex formed (Pd-HHB) must be studied to approach the actual mechanism of flotation. The proposed mechanism may proceed through a physical interaction or by forming a hydrogen bond between the hydrophilic part of HOL and the active sites in the ligand complex, or by an interaction between oleic acid and the complex, formed in solution, through a coordinate bond forming a self-floatable (Pd-HHB-HOL) species. In such cases, the hydrophobic part of the surfactant attaches to air bubbles and floats, thus separating the analyte-containing species.

In our investigation, the first proposal is more logical. This suggestion has been confirmed based on the following observations and experimental data: 1) The palladium content of the solid complexes isolated in the 


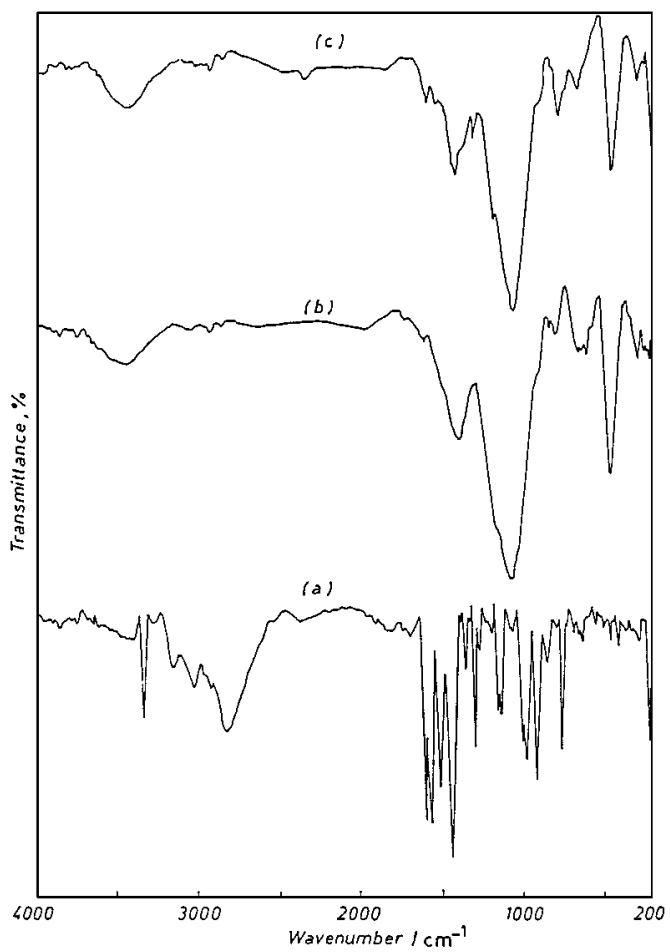

Fig. 7 Infrared spectra of a) $\mathrm{HHB}$ in $\mathrm{KBr}$, b) $\mathrm{Pd}(\mathrm{III})-\mathrm{HHB}$ isolated in aqueous solution in $\mathrm{KBr}$ and c) $\mathrm{Pd}(\mathrm{II})-\mathrm{HHB}-\mathrm{HOL}$ isolated in oleic acid in $\mathrm{KBr}$.

absence and presence of HOL excludes HOL coordination. 2) The floated species have the same color (violet) as that obtained in the aqueous solution (especially in high reactants concentrations). 3) The color intensity of the scum layer was affected by time. It should be noted that the color fading of the sublate begins after at least $5 \mathrm{~h}$ after flotation; such a time is more than enough for our determination. 4) The data in Fig. 6 show that increasing the temperature decreases the separation percentage, reflecting that the physical force between HOL and the Pd-HHB complex is destroyed by heating. 5) The ir spectra of the Pd-HHB complex isolated in the absence and presence of HOL are identical (Fig. 7), reflecting the fact that there is no coordinate or hydrogen contribution between HOL and the Pd-HHB complex. In conclusion, all of the mentioned studies confirm the first proposal mechanism, and a

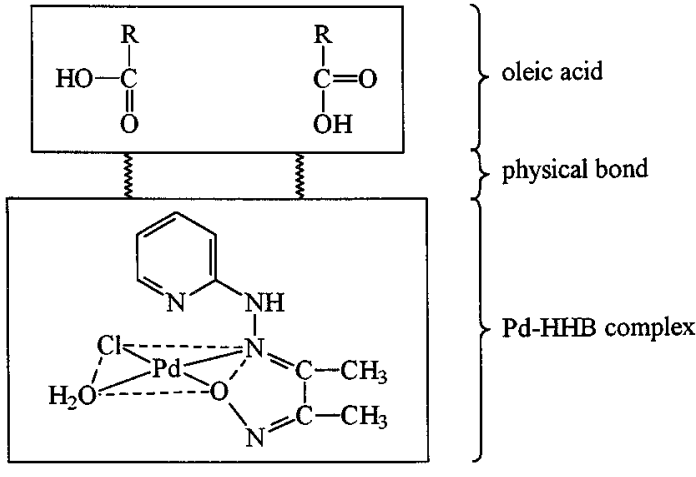

Fig. 8 Schematic representation of the sublate structure.

sublate structure may be represented as in Fig. 8 .

\section{Application}

Separation and determination of Pd(II) in some complexes, simulated and water samples. Accurately, about $0.02 \mathrm{~g}$ of the complex sample of Pd was taken and heated until evaporation in $5 \mathrm{ml} \mathrm{HNO}_{3}$ for dissolution. A cold solution was completed to $50 \mathrm{ml}$ using doubly distilled water. Into a flotation cell, $0.5 \mathrm{ml}$ of such a solution was introduced. To this, $2 \mathrm{ml}$ of HHB $\left(1 \times 10^{-3} \mathrm{~mol} \mathrm{l}^{-1}\right.$ was added, and the volume was completed to $10 \mathrm{ml}$ with doubly distilled water after adjusting the $\mathrm{pH}$ to $\approx 2.5$. After the cell was shaken for $30 \mathrm{~s}$ to ensure complete complexation, $3 \mathrm{ml}$ of oleic acid $\left(2.0 \times 10^{-4} \mathrm{~mol} \mathrm{l}^{-1}\right)$ was added, and the cell was inverted upside down (by hand) twenty times for complete flotation. Two minutes after flotation was found to be sufficient to obtain a clear-violet scum layer. Such a layer was separated and an appropriate volume was introduced into the spectrophotometer cell for palladium determination at $555 \mathrm{~nm}$. The analyte content was calculated from the calibration curve, which was constructed by taking different concentrations of $\mathrm{PdCl}_{2}$ covering the basic range up to $10 \mathrm{ppm}$ palladium. The same aforementioned steps for flotation and determination were carried out. In all measurements, the concentration of HHB as in the test solution was used as a blank. The results are listed in Table 1.

It is well established in the literature ${ }^{5,17}$ that the spectrophotometric determination of Pd after solvent extrac-

Table 1 Comparative results for the analysis of palladium in various complexes in the presence of $2 \times 10^{-4}$ mol $1^{-1} \mathrm{HHB}$ using $2 \times 10^{-4} \mathrm{~mol} \mathrm{l}^{-1} \mathrm{HOL}$

\begin{tabular}{|c|c|c|c|c|c|c|}
\hline \multirow{2}{*}{ Complex } & \multicolumn{2}{|c|}{$\operatorname{Pd}(\mathrm{II}), \mathrm{ppm}$} & \multirow{2}{*}{ Abs.E } & \multirow{2}{*}{ R.E. } & \multirow{2}{*}{ SD } & \multirow{2}{*}{ RSD } \\
\hline & Calculated & Found & & & & \\
\hline$\left[\mathrm{Pd}(\mathrm{HPAPTS})_{2}\right]$ & 2.53 & 2.55 & +0.02 & 0.79 & 0.016 & 0.63 \\
\hline$\left[\mathrm{Pd}(\mathrm{HPxAPTS})_{2}\right]$ & 2.4 & 2.42 & +0.02 & 0.83 & 0.017 & 0.69 \\
\hline$\left[\mathrm{Pd}(\mathrm{HBMPH})_{2}\right]$ & 5.95 & 5.99 & +0.04 & 0.67 & 0.01 & 0.17 \\
\hline$\left[\mathrm{Pd}\left(\mathrm{H}_{2} \mathrm{BMPH}\right) \mathrm{Cl}_{2}\right]$ & 4.14 & 4.16 & +0.02 & 0.48 & 0.02 & 0.48 \\
\hline
\end{tabular}

$\mathrm{H}_{2}$ PAPTS denotes phenylacetyl 4-phenyl 3-thiosemicarbazide; $\mathrm{H}_{2} \mathrm{BMPH}$, biacetyl monoximephenylacetyl hydrazone; $\mathrm{H}_{2} \mathrm{PxAPTS}$, 1-phenoxyacetyl-4-phenyl-4-phenyl-3-thiosemicarbazide. 
Table 2 Comparative results for the analysis of $\mathrm{Pd}(\mathrm{II})$ in simulated silver alloy

\begin{tabular}{ccc}
\hline Composition, \% & \multicolumn{2}{c}{ Pd, \% } \\
& Certificate & Present method \\
\hline $\mathrm{Ag}, 99.9$ and $\mathrm{Cu}, 0.049$ & 0.048 & 0.048 \\
\hline
\end{tabular}

Table 3 Determination of $\mathrm{Pd}(\mathrm{II})$ in natural water by spectrophotometric and colorimetric method after flotation using $2 \times 10^{-4} \mathrm{~mol} \mathrm{l}^{-1} \mathrm{HHB}$ and $2 \times 10^{-4} \mathrm{~mol} \mathrm{l}^{-1} \mathrm{HOL}$ at $\mathrm{pH} 3.5$

\begin{tabular}{|c|c|c|c|}
\hline \multirow{2}{*}{$\begin{array}{c}\mathrm{Pd}(\mathrm{II}) \\
\text { added/ } / \mu \mathrm{g}\end{array}$} & \multicolumn{2}{|c|}{$\operatorname{Pd}\left(\right.$ II) found $/ \mu \mathrm{g}^{\mathrm{a}}$} & \multirow{2}{*}{ Recovery, \% } \\
\hline & Spectrophotometric & Colorimetric & \\
\hline \multicolumn{4}{|l|}{ Bidistilled water } \\
\hline 2 & 2 & 2 & 100 \\
\hline 3 & 3 & 3 & 100 \\
\hline 8 & 7.98 & 7.98 & 99.8 \\
\hline \multicolumn{4}{|l|}{ Tap water } \\
\hline 2 & 2 & 2 & 99.9 \\
\hline 3 & 3 & 3 & 100 \\
\hline 8 & 7.8 & 7.8 & 99.8 \\
\hline \multicolumn{4}{|l|}{ Tank water } \\
\hline 2 & 2.02 & 2.02 & 101 \\
\hline 3 & 3 & 3 & 100 \\
\hline 8 & 7.8 & 7.8 & 99.8 \\
\hline \multicolumn{4}{|c|}{ Nile water (Mansoura city) ${ }^{\mathrm{b}}$} \\
\hline 2 & 2 & 2 & 100 \\
\hline 3 & 2.99 & 2.99 & 99.8 \\
\hline 8 & 7.98 & 7.98 & 99.8 \\
\hline \multicolumn{4}{|c|}{ Nile water (Belkas city) } \\
\hline 2 & 2.02 & 2.02 & 101 \\
\hline 3 & 3 & 3 & 99.8 \\
\hline 8 & 7.9 & 7.9 & 99 \\
\hline \multicolumn{4}{|c|}{ Nile water (Talkha city) ${ }^{\mathrm{b}}$} \\
\hline 2 & 2.04 & 2.04 & 102 \\
\hline 3 & 3 & 3 & 100 \\
\hline 8 & 8 & 8 & 100 \\
\hline
\end{tabular}

a. The average of three readings. b. Location.

tion is hampered by the presence of silver. Thus, the applicability of this procedure was extended to the determination of $\operatorname{Pd}(\mathrm{II})$ in a simulated silver alloy (Table 2). In order to investigate the applicability to a natural-water sample, the recoveries of known amounts of $\mathrm{Pd}(\mathrm{II})$ added to bidistilled, domestic and river water samples were examined by such a procedure. To $20 \mathrm{ml}$ aliquots of clear uncontaminated, filtered water samples 2, 3 and $8 \mu \mathrm{g}$ of $\mathrm{Pd}(\mathrm{II})$ were added and the $\mathrm{pH}$ was adjusted by $\mathrm{HCl}$ to $\mathrm{pH}$ 3.5. After flotation (as previously mentioned), the scum ( $3 \mathrm{ml} \mathrm{HOL}$ ) was taken up and measured spectrophotometrically (at $555 \mathrm{~nm}$ ) or colorimetrically (at $550 \mathrm{~nm}$ ) for Pd(II) determination. The results are given in Table 3. It is worthy noting that, a parallel series of the same experiments were carried out under the same conditions, and that the palladium content was completely eluted and introduced directly for a $\mathrm{Pd}(\mathrm{II})$ atomic absorption determination as a confirmatory test. The results revealed that high confirmation is gained. The data given in Table 3 demonstrate that the technique is applicable to the analysis of $\operatorname{Pd}(\mathrm{II})$ in different water samples, and is satisfactory. Moreover, a comparison of the spectrophotometric measurements with the results obtained colorimetrically reveals that the method is very simple and economic. Also, the determination after flotation makes the process highly selective and sensitive.

\section{References}

1. F. E. Beamish, "The Analytical Chemistry of the Noble Metals", Pergamon Press, Toronto, 1966.

2. F. E. Beamish, J. C. van Loon, "Recent Advances in The Analytical Chemistry of the Noble Metals", Pergamon Press, Toronto, 1977.

3. R. S. Young, Analyst [London], 76, 49 (1951).

4. A. S. Lee, F. E. Beamish and M. G. Bapat, Mikrochim. Acta, 329, 1969.

5. Z. Marczenko and J. M. Jarosz, Analyst [London], 106, 751 (1981).

6. M. Ohta, K. Hisatsumke and M. Yamane, J. Less Common Metals, 65, 11 (1979).

7. W. E. Gardner, I. Penfold, T. F. Smith and I. R., J. Phys. F., 2, 123 (1972).

8. O. Loebich, Jr. and E. Raub, J. Less Common Metals, 39, 55 (1975).

9. M. A. Kabil, S. E. Ghazy, A. A. El-Asmy and Y. E. Sherif, Anal. Sci., 12, 431 (1996).

10. S. E. Ghazy, M. A. Kabil and M. A. Mostafa, J. Anal. At. Spectrom., 9, 857 (1994).

11. S. E. Ghazy, M. A. Kabil, A. A. El-Asmy and Y. A. Sherif, Anal. Lett., 29, 1215 (1996).

12. M. E. Khalifa, Analusis, 23, 453 (1998).

13. X. He, Talanta, 38 (1991).

14. Lemlich (ed.), "Adsorptive Bubble Separation Techniques", Academic Press, New York, 1972.

15. M. A. Mostafa, M. A. Kabil, A. M. Shallaby and T. I. Zaid, Analusis, 25, 119 (1997).

16. P. Job and C. R. Hebd, Sceances Acad. Sci., 180, 928 (1925); Ann. 9, 113, 1928.

17. R. S. Young, Analyst [London], 76, 49 (1951).

(Received November 30, 1998) (Accepted February 8, 1999) 